\title{
Abordagem temática freireana: a superação de obstáculos gnosiológicos na formação de professores
}

\section{Freirean thematic approach: Overcoming gnosiological obstacles in teacher training}

\author{
Manuela Gomes Bomfim \\ Simoni Tormöhlen Gehlen \\ Universidade Estadual de Santa Cruz (UESC), Brasil
}

\section{Resumo}

Algumas pesquisas realizadas no Brasil, baseadas em Paulo Freire, têm discutido sobre situações limítrofes que professores de Ciências têm apresentado no desenvolvimento de práticas pedagógicas. Essas situações, denominadas de Obstáculos Gnosiológicos, são caracterizadas como barreiras para que os professores possam implementar um currículo crítico. Objetiva-se investigar a superação desses obstáculos manifestados por professores da Educação de Jovens e Adultos (EJA), que participaram de um Processo Formativo de professores, em uma escola pública em Ilhéus/BA-Brasil. As atividades deste processo de formação foram estruturadas tendo como referência as etapas da Investigação Temática Freireana, na obtenção de Temas Geradores. As informações foram obtidas por meio de videogravações dos encontros do Processo Formativo e analisadas por meio da Análise Textual Discursiva, tendo como categorias: Medo da Liberdade, Negação da Descontinuidade Epistemológica como Gênese, Pretensão à Verdade e Arrogância Epistemológica. Dentre os resultados, constatou-se que durante o Processo Formativo os professores apresentaram indicativos da superação desses Obstáculos, principalmente nas etapas da Legitimação da Hipótese e Organização da Programação Curricular, sinalizando para o potencial Gnosiológico da Abordagem Temática Freireana.

Palavras-chave: ensino de ciências; formação de professores; potencial gnosiológico, Paulo Freire.

\begin{abstract}
Some researches conducted in Brazil, based on Paulo Freire, have discussed about borderline situations that teachers of Science have presented in the development of pedagogical practices. These situations, called Gnosiological Obstacles, are characterized as barriers for teachers to implement a critical curriculum. The objective is to investigate the overcoming of these obstacles manifested by teachers of the Education of Youths and Adults (EJA), who participated in a Formative Process of teachers, in a public school in IIhéus/BA-Brasil. The activities of this training process were structured with reference to the stages of the Freirean Thematic Research, in obtaining Generator Themes. The information was obtained through videotapes of all the meetings of the Formative Process and analyzed through Discursive Textual Analysis, having as categories: Fear of Freedom, Denial of Epistemological Discontinuity as Genesis, Pretension to Truth and Epistemological Arrogance. Among the results, it was observed that during the Formative Process teachers presented indicatives of overcoming these Obstacles, mainly in the stages of Legitimation of Hypothesis and Organization of Curricular Programming, signaling to the Gnosiological potential of the Freirean Thematic Approach.
\end{abstract}

Keywords: science teaching; teacher training; gnosiological potential, Paulo Freire. 


\section{INTRODUÇÃO}

Alguns trabalhos na área de Ensino de Ciências realizados no Brasil têm se apoiado nos pressupostos de Paulo Freire para discutir aspectos relacionados à reestruturação curricular, com base em Temas Geradores, na formação inicial e continuada de professores, a exemplo de Delizoicov (1982), Sousa, Solino, Figueiredo e Gehlen (2014) e Lambach (2013). O Tema Gerador apresenta em sua essência situações-limites, compreendidas como obstáculos apresentados pelos indivíduos, que se estabelecem como barreiras para que os mesmos possam apresentar uma compreensão humanizadora do contexto social em que está inserido (Freire, 1987). Parte dos estudos, balizados nos pressupostos freireanos, discutem aspectos relacionados a situações limítrofes que professores de Ciências têm apresentado no desenvolvimento de práticas pedagógicas, caracterizadas por Alves e Silva (2015) como Obstáculos Gnosiológicos. Os autores afirmam que esses Obstáculos podem ser superados em processos de formação permanente, se estruturados a partir dos pressupostos teórico-metodológicos da Abordagem Temática Freireana, priorizando o diálogo e a problematização. Essa Abordagem consiste em uma perspectiva de reconfiguração curricular estruturada a partir do Tema Gerador, que representa as principais problemáticas da comunidade. Dessa forma, os conteúdos, conceitos e conhecimentos

30 são selecionados a partir das demandas apresentadas para compreensão do Tema.

No entender de Stuani (2016), a Abordagem Temática Freireana, enquanto concepção de formação permanente, apresenta seu potencial Gnosiológico associado à problematização e a aprendizagem constante dos sujeitos com elementos de seu contexto. A autora afirma que ao tomar a realidade do sujeito como ponto de partida, exige que o docente esteja apto a realizar problematizações crítico-reflexivas de sua própria prática, ressaltando que no contexto da formação permanente a "problematização da própria prática de forma coletiva propicia o desencadear de um processo de conscientização, que faz do professor um sujeito pensante e não um mero expectador (Stuani, 2016, p. 232)". Tendo em vista que o Potencial Gnosiológico da Abordagem Temática Freireana na formação permanente tem como essência a problematização e a dialogicidade (Stuani, 2016), corrobora-se com a ideia que esses elementos terão um importante papel na superação dos Obstáculos Gnosiológicos. Com isso, objetiva-se identificar indicativos da superação dos Obstáculos Gnosiológicos manifestados por professores da EJA, em um Processo Formativo, realizado no município de Ilhéus/BA, região Nordeste do Brasil. 


\section{OBSTÁCULOS GNOSIOLÓGICOS}

De acordo com Japiassu e Marcondes (2001), Gnosiologia compreende a teoria do conhecimento, que tem como ponto de partida a busca da origem, da natureza, dos valores e dos limites do conhecimento humano. Damke (1995) argumenta que Gnosiologia, baseado nas ideias de Paulo Freire, é o ato de conhecer que ocorre por meio da interação social, sendo mediatizado pelo diálogo. Esse diálogo, para Freire (1987), está relacionado com a construção do conhecimento no contexto da educação libertadora, superando a relação oprimido e opressor, vigente na educação bancária. Assim, o diálogo se constitui como condição sine qua no para a educação libertadora, uma vez que "sem ele [diálogo], não há comunicação e sem esta não há verdadeira educação" (Freire, 1987, p 83).

Para Freire (1996), a educação como prática da liberdade é verdadeiramente uma situação gnosiológica, possibilitando que o homem perceba-se como ser inacabado, em constante construção, sendo o diálogo um dos elementos essências deste contexto. Para ele:

Na educação que seja verdadeiramente uma situação gnosiológica, não há para o educador, um momento em que, sozinho, em sua biblioteca ou em seu laboratório, conheceu, e outro em que, afastado deste, simplesmente narra, disserta ou expõe o que conheceu (Freire, 1996, p 79).

Isto é, na visão de Freire (1996), a educação como uma situação gnosiológica, baseada no diálogo, fomenta a construção do conhecimento de forma colaborativa, em que educando e educador assumem a postura de sujeitos cognoscentes. Nessa perspectiva, o educador afasta-se da cultura do ensino bancário, priorizando a troca e a busca de novos conhecimentos, por meio do diálogo com os educandos. Nessa relação, o educador não é narrador ou transmissor de conteúdo; ele passa ser responsável pela problematização dos conteúdos que se apresentam na relação entre os seres cognoscentes (Freire, 1996).

Damke (1995), baseado nos pressupostos freireanos, afirma que a situação gnosiológica não está restrita na relação entre o sujeito e o objeto, mas ocorre na dialogicidade entre o educando e educador, enquanto seres cognoscentes, mediado pelo objeto cognoscível. Stuani (2016) afirma que aprender com a cotidianidade envolve a dimensão gnosiológica da perspectiva freireana, uma vez que ocorre a reconstrução do conhecimento a partir das mudanças e demandas do contexto que os sujeitos estão inseridos. Damke (1995) também explica que a problematização apresenta-se como uma exigência da situação gnosiológica, pois possibilita aos educandos exercitarem o pensar criticamente e interpretarem o contexto social em 
que estão inseridos. E Freire (1996) entende que é no ato de problematizar que o docente problematiza a si mesmo, pois é impossível questionar algo para alguém sem comprometer-se com o processo. Nesse sentindo, o professor está inserido em um contexto, no qual os questionamentos se configuram como uma situação de reaprendizagem, possibilitando a revisão do conhecimento.

Stuani (2016) aprofunda as discussões sobre a concepção de gnosiologia em Freire e destaca que:

\begin{abstract}
A gnosiologia presente na educação freireana concebe a interrelação entre os saberes numa dimensão social do conhecimento, que se coloca a serviço da humanização. Nesta perspectiva, o problema é um elemento desencadeador de novas reflexões acerca da ação docente, no sentido de trazer novos desafios a serem enfrentados na busca dialógica pela elaboração do conhecimento (Stuani, 2016, p. 230).
\end{abstract}

Isto é, a situação gnosiológica, no entender da autora, apresenta-se pela troca do conhecimento entre os sujeitos, tendo o problema como desencadeador da busca por novos conhecimentos. Para Stuani (2016), além de levar em consideração os problemas sociais vivenciados pelos sujeitos, na educação verdadeiramente gnosiológica, é necessário que haja diálogo crítico sobre esses problemas, bem como a interlocução de novos conhecimentos para a compreensão dos mesmos.

Alves (2014), baseado nas relações teóricas entre Gaston Bachelard, Ludwick Fleck e Paulo Freire, cunha o termo "Obstáculos Gnosiológicos" entendido como "limites na concepção dos educadores, impedindo-os de implementarem um currículo crítico de ciências" (Alves e Silva, 2015, p. 187). Isto é, os Obstáculos apresentam-se como situações-limite, que representam a visão limitada e acrítica dos educadores que constituem como barreiras para construção e implementação de um currículo crítico-reflexivo. De acordo com Alves (2014), esses obstáculos podem ser de diferentes naturezas, quais sejam:

- Medo da Liberdade: ocorre quando a autonomia e autenticidade dos docentes em sala de aula ficam comprometidas, para entender às demandas da cultura hegemônica, que no caso dos educadores correspondem aos interesses do Estado.

- Pretensão da Verdade: no contexto escolar é manifestado quando os docentes não desenvolvem o processo de ensino e aprendizagem a partir das problemáticas vivenciadas pelos alunos.

- Arrogância Epistemológica: ocorre à medida que os educadores assumem o papel de transmitir o conhecimento para os alunos, os quais não são considerados sujeitos ativos no processo de ensino e aprendizagem. 
- Negação da descontinuidade Epistemológica como Gênese do Conhecimento: se manifesta no contexto de sala de aula, quando os docentes não exploram as tensões e os conflitos que perpassaram a construção do conhecimento, por não considerar relevante ou por entender que a discussão dessas questões demanda um tempo que não está disponível, em função da "necessidade" em cumprir toda a grade curricular.

Bomfim (2018) realizou um estudo inicial com professores da EJA de uma escola pública localizada no distrito de Olivença, município de Ilhéus, no estado brasileiro da Bahia, em que por meio de entrevistas, identificou esses quatros Obstáculos Gnosiológicos, sinalizando a necessidade de realizar um Processo Formativo, baseado na Abordagem Temática Freireana, para a superação desses Obstáculos.

\section{ENCAMINHAMENTOS METODOLÓGICOS}

Após identificar a manifestação dos Obstáculos Gnosiológicos em professores que atuam na EJA, conforme apresentado por Bomfim (2018), desenvolveu-se um Processo Formativo de professores em parceria com o GEATEC .Aformaçãofoirealizadacomseteprofessores, nasdependências daescolaemqueatuam os professores entrevistados por Bomfim (2018), durante oito encontros correspondendo a 40 horas de atividades, em Olivença, Distrito de Ilhéus/BA. O Processo Formativo foi realizado tendo como referência a Investigação Temática (Freire,1987), com base nas etapas de Sousa et al. (2014), quais sejam:

1. Aproximações iniciais com a comunidade local e escolar: realizou-se algumas visitas a escola com o objetivo de apresentar a proposta aos professores e firmar uma parceria. Na sequência foram obtidas informações com os moradores e nos blogs regionais de notícias sobre as principais problemáticas que permeiam a comunidade de Olivença;

2. Apresentação de possiveis situações-limite para a comunidade local: identificouse possíveis situações-limite da comunidade, envolvendo uma compreensão acrítica e limitada, acerca de questões relacionadas à atividade de extração de areia e seus impactos para o meio ambiente, bem como um posicionamento acrítico e acomodado com relação aos assuntos de violência, infraestrutura e a falta do sentimento de pertencimento dos moradores daquela região. Essas informações foram organizadas em um portfólio, o qual foi apresentado para a comunidade com o objetivo de identificar a concepção dos moradores e do Poder Público com relação aos problemas apontados;

3. Legitimação da hipótese: realizou-se a legitimação das situações-limites com os professores, alunos, moradores e integrantes do poder público do 
município de Ilhéus e obteve-se o Tema Gerador 'Olivença: eu vivo em um paraíso esquecido', selecionado pelo fato de envolver as problemáticas locais.

4. Organização da Programação Curricular: construiu-se uma Rede Temática, adaptada de Silva (2004), que auxiliou na organização e problematização de práticas educativa, conteúdos, conceitos científicos e ações necessárias para superar as situações-limite. Organizou-se a estruturação do conteúdo em um Plano de Ensino, compreendendo três unidades: "Identidade histórica de Olivença", "Impactos Socioambientais" e "Infraestrutura e Economia", contemplando conteúdos da área de história, geografia, literatura, matemática, física, química e biologia.

Para a obtenção das informações durante o Processo Formativo, realizou-se videogravações dos oito encontros na íntegra, que foram analisadas por meio da Análise Textual Discursiva (Moraes e Galiazzi, 2011), tendo como categorias a priori os Obstáculos Gnosiológicos: "Medo da Liberdade", "Negação da Descontinuidade Epistemológica como Gênese do Conhecimento", "Pretensão à Verdade Científica" e "Arrogância Epistemológica". Para preservação da identidade dos sujeitos, os nomes dos professores e pesquisadores que participaram das entrevistas e do Processo Formativo foram substituídos pela letra P (professor), seguido por um "numeral": P1, P2, Pn... sendo que D1 corresponde ao vice-diretor. Para identificar os pesquisadores utilizou-se PQ (pesquisador), seguido por um "numeral": Pq1, Pq2, Pqn.

\section{INDICATIVOS DA SUPERAÇÃO DOS OBSTÁCULOS GNOSIOLÓGICOS
4.1 Negação da descontinuidade epistemológica como gênese do conhecimento

No estudo de Bomfim (2018), alguns professores apresentaram a manifestação do Obstáculo Gnosiológico Negação da Descontinuidade Epistemológica como gênese do conhecimento. Isto ocorreu quando os docentes atribuíam neutralidade à produção do conhecimento científico, negando as tensões e conflitos que perpassam sua produção como uma construção histórico-cultural (Alves, 2014). Por outro lado, na etapa da Legitimação da Hipótese, que é o momento em que se obtém o Tema Gerador, os professores apresentaram indicativos da superação do deste Obstáculo, como é possível identificar no extrato da fala de P5:

Esse tema abrange a peculiaridade do local. A falta desse reconhecimento (do potencial de Olivença) tem levado a desvalorização por parte da comunidade. Entender que viver em um lugar tão rico acarreta em uma responsabilidade cultural e social relevante fará toda diferença na ação em defesa dos valores locais. A população fica inerte com relação às situações como poluição, droga, 
conflitos agrários pelo desconhecimento de sua história. Resgatar essa força do passado, junto com a aplicação de novos conhecimentos abrirá novas possibilidades (P5) (Grifo nosso).

No entender de P5, o resgate do contexto histórico associado a novos conhecimentos abre novas possibilidades, ou seja, conhecer as questões históricas de Olivença auxiliará os sujeitos compreenderem os fatos atuais que influenciam diretamente na economia e infraestrutura da comunidade. Com base em Alves (2014), nota-se que P5 apresenta indicativos da superação da Negação Epistemológica, vinculado ao afastamento da postura conservadora, uma vez que, ao afirmar a necessidade do resgate histórico, o mesmo contribui para a reprodução e conservação de uma epistemologia que tem nos aspectos históricos a gênese do conhecimento, negando a neutralidade e a linearidade do contexto de Olivença. Corroborando com essa ideia, P2 afirma:

Acho interessante que dentro desta temática seja trabalhando a autoestima, os direitos e deveres, a identidade [referindo-se ao resgate histórico] e a consciência ambiental dos alunos, que podem se tornar agentes transformadores de sua comunidade. (P2) (Grifo nosso).

P2 argumenta que há necessidade de resgatar os aspectos históricos que permeiam a comunidade, ressaltando que os fatos ocorridos no passado, influenciam a dinâmica atual do Distrito, bem como as ações dos sujeitos que ali residem. Constata-se a superação em algumas compreensões de P2, quando aponta que: "Interessante que dentro desta temática seja trabalhando a autoestima, os direitos e deveres, a identidade [referindo-se ao resgate histórico] (P2)".

P2 percebe que para a compreensão do Tema Gerador, algumas discussões sobre o histórico de Olivença, direitos e deveres dos cidadãos tornam-se imprescindíveis. Alves (2014), fundamentada nas bases epistemológicas de Paulo Freire, afirma que a construção do conhecimento não ocorre de maneira aleatória, mas conforme as demandas dos problemas apresentados na realidade do sujeito, que no caso de P2, refere-se às situações-limite que constituem o Tema Gerador de Olivença.

Na etapa da Organização da Programação Curricular, em que foram construídas as Unidades de Ensino, P3 afirma: "Olha alí, naquela unidade [se referindo à primeira Unidade], eu posso trazer aspectos da história de Olivença e de Ilhéus para discutir os assuntos do romantismo. (P3) (Grifo nosso)." Nessa etapa, os professores elaboraram as Unidades de Ensino, em que na Unidade I denominada "Identidade histórica de Olivença" aborda-se a questão histórica da comunidade, e conteúdos relacionados à Desvalorização da cultura local, Demarcação das terras 
Indígenas, Valorização da cultura local, Conflitos identitário/preconceito e Conflito territorial. Sendo que o objetivo foi compreender os aspectos históricos, bem como analisar os reflexos dos mesmos nos problemas atuais da comunidade de Olivença.

Levando em consideração as características apresentadas pelos tópicos na Unidade I, P3 afirmou que pode resgatar os aspectos da história local para trabalhar o conteúdo de sua disciplina de Literatura, de modo que fique evidente para os alunos de que forma os conflitos e tensões do passado influenciaram nos problemas atuais da comunidade . No entender de Freire (1968), é por meio dessa troca entre educador e educando, sustentado pelo conhecimento científico, que ocorre a construção do conhecimento acerca da realidade, que no contexto de P3 corresponde aos conteúdos necessários para a compreensão do Tema Gerador. Para o autor, essa prática está vinculada a uma concepção epistemológica que considera os problemas socioculturais, como ponto de partida para construção de novos conhecimentos. Assim, os conteúdos escolares selecionados a partir da demanda concreta da comunidade de Olivença ganham sentindo e significado tanto para o educador quanto para o educando, tornando-se conteúdo concreto e instrumento de transformação cultural.

\subsection{Medo da Liberdade}

No estudo de Bomfim (2018), professores também manifestaram o Obstáculo Gnosiológico Medo da Liberdade, ao assumirem uma postura passiva, acrítica, carente de problematização e seguiram sugestões estabelecidas pelos documentos oficiais, dificultando a implementação de um currículo crítico.

$\mathrm{Na}$ etapa da Aproximação inicial com a comunidade local e escolar, realizou-se problematizações com os professores por meio do vídeo "A coroa do Imperador" queretratapartedarealidadedaeducaçãopúblicanoBrasil. Pormeio deproblematizações , buscou-se compreender as visões que os docentes tinham sobre aspectos como: concepção de educando, planejamento de aula e papel do professor em sala de aula. Quando questionados sobre a importância da participação do educando e o diálogo no processo de ensino e aprendizagem, alguns docentes se posicionaram da seguinte forma:

Na EJA, eu dou os conteúdos próprios da EJA, tirando o eixo 5. Eu comecei a trabalhar um conteúdo com eles, que é equação do segundo grau, que eles têm muita dificuldade. Então, assim, eu pulo um conteúdo e dou outro, mas dentro do conteúdo deles, dentro do próprio livro que é proposto, que a escola tem como proposta. (P1) (Grifo nosso). 
Corroborando com essa fala, P4 afirma:

Eu também faço a seleção. A gente tem o material da EJA que, por sorte, ele já traz muita coisa contextualizada. Depois que chegou esse material pra EJA mesmo, eu acho que facilitou essa questão da gente selecionar. Até a parte temática, eles já trazem identidade, e como você vai trabalhar cada tema. Então isso já ajuda muito. O que a gente faz? Eu sigo aquele conteúdo que foi eleito (P4) (Grifo nosso).

As afirmações de P1 e P4 denotam que a seleção dos conhecimentos científicos que serão trabalhados em sala de aula está associada com os conteúdos estabelecidos pelos livros didáticos ou documentos oficiais. Nessa condição, os educadores renunciam sua autonomia, tornando-se objetos e não mais sujeitos ativos (Alves, 2012).

Para Alves (2014, p. 101), "as práticas docentes pouco autônomas, baseadas pela reprodução de conteúdos pré-estabelecidos e distantes da realidade dos educandos", são caracterizadas como Obstáculo Gnosiológico do Medo da Liberdade. Ao apresentar certo medo à prática autônoma, conforme constatado nas falas de P1 e P4, os docentes acabam por subordinarem-se aos interesses da cultura hegemônica que valoriza determinados conteúdos, sem considerar as necessidades reais da comunidade escolar. Ao encontra-se imerso nesse Obstáculo, o sujeito internaliza as verdades imposta pelo dominador como única, em consequência não assume sua autonomia e autenticidade. No entender de Dussel (1995), à medida que o sujeito não tem voz, não respeita a sua história ou a sua cultura, não Ihe é permitido ser sujeito, passando a ser incorporado pela "totalidade alheia". Para o autor, "totalizar a exterioridade, sistematizar a alteridade, negar o outro como outro é alienação" (Dussel, 1995, p.60). Nesse sentindo, quando o sujeito está submetido à totalidade da cultura hegemônica, passa ser objeto do dominador, perdendo a sua essência, autonomia e autenticidade, tornando-se instrumento do ser de outro.

Para Freire (1987), esses sujeitos subordinados à condição de oprimidos, apresentam-se nas sombras dos opressores, à medida que seguem o que esses thes determinam. Assim, infere-se que, P1 e P4 "temem a liberdade, na medida em que esta, implicando a expulsão desta sombra, exigiria deles que "preenchessem" o "vazio" deixado pela expulsão com outro "conteúdo" - o da autonomia", com isso o Medo de assumir sua liberdade associa-se ao fato de torna-se responsável pelas próprias ações. 
Baseando-se em Alves e Silva (2015, p.182), o Medo da Liberdade manifestado nas falas de P1 e P4 compreende aspectos que transcendem a formação, tais como "a cultura escolar arraigada na tradição educacional, limites no tempo de preparação das atividades pedagógicas, salários baixos que exigem jornadas de trabalhos exaustivas, etc.". Os autores ressaltam que o Medo apontado pelos docentes está ligado ao posicionamento político dos mesmos, uma vez que, ao adotar uma prática excludente estabelecida historicamente, passam a defender concepções, que fortalecem a imposição da cultura hegemônica.

Na etapa da Apresentação de possíveis Situações-limite constatou-se, por meio da problematização do vídeo "Bem vindo (a) a Olivença", evidências de autonomia dos professores em sala de aula. Ao questionar a possibilidade de trabalhar com os alunos as informações da aproximação inicial e do vídeo, os professores se posicionaram da seguinte forma:

Esses temas?... Acredito que sim. (P6),

De certa forma, alguns desses temas são trabalhados, mas não com tanta densidade... (P5) (Grifo nosso).

Quando questionado de que maneira esse trabalho acontece, P5 afirma:

A gente conversa, ou seja, até que a gente tem algumas informações. Por exemplo, eu não moro aqui, mas eu já conheço bastante coisa por conta do debate que a gente faz aqui, que eles trazem as angústias, as preocupações... Mas, organizado dessa forma, a gente, realmente, não tinha trabalhado... (P5) (Grifo nosso).

As falas dos professores expressaram certa dúvida sobre o trabalho desenvolvido a partir dos temas. Todavia, $\mathrm{P} 5$ ressalta que embora não morasse na região, trabalhava alguns aspectos da realidade, por meio das informações adquiridas em conversas com os alunos. No entanto, o diálogo estabelecido entre P5 e seus alunos não ocorre de forma sistematizada, ou seja, o professor não organiza as informações sobre a realidade da comunidade para que possam ser trabalhadas em sala de aula. Para Stuani (2016), não é suficiente partir da realidade dos alunos, uma vez que é preciso um diálogo crítico sobre as situações-limite vivenciadas pelos sujeitos, bem como a interlocução de novos conhecimentos necessários para a compreensão das mesmas. Esse diálogo desenvolvido por P5 diverge da concepção freireana, a qual defende que o diálogo estabelecido entre educador e educando ocorre por meio da problematização da realidade concreta dos sujeitos. Freire (1987) argumenta que: 
O que se pretende com o diálogo, em qualquer hipótese (seja em torno de um conhecimento científico e técnico, seja de um conhecimento "experiencial"), é a problematização do próprio conhecimento em sua indiscutível reação com a realidade concreta na qual se gera e sobre a qual incide, para melhor compreende- lá, explica - lá, transforma - lá (Freire, 1987, p.34).

O processo de Investigação Temática apresenta-se como uma alternativa para superação da situação expressa na fala de P5, uma vez que na Redução Temática (quarta etapa da Investigação), serão elencadas ações, conteúdos e conhecimentos científicos necessários para a compreensão do Tema Gerador. Apesar de na segunda etapa da Investigação Temática, constar-se manifestações incipientes de autonomia dos professores, os extratos das falas apontam para uma possivel progressão desta postura para nas próximas etapas da Investigação Temática.

Na terceira etapa do Processo Formativo, juntamente com os professores foram problematizadas as situações-limite de Olivença, objetivando-se a Legitimação do Tema Gerador. Nesse momento, os educadores apresentaram-se apreensivos, seguidas de um intervalo de silêncio, denotando insegurança para eleição do Tema Gerador. Até que P5 posicionou-se:

Eu acho que [...] do que foi apresentado, eu acho que a questão da cidadania é algo que precisa ser trabalhado. O que vocês acham? Porque é uma questão que [...] é abrangente. (P5).

Na sequência, outros professores apresentaram aspectos que poderiam ser discutidos:

Os próprios valores né?! [...] Talvez a questão de identidade (P6).

Violência. Porque eles pensam que violência é só homicídio (D1).

Eu acho que "Identidade e Pertencimento". Eu acho que é um tema mais aberto (P5).

Assim, pelo portfólio, pela fala dos moradores, eu vi que o "Meio Ambiente" está em todas (falas). Agora assim, eu entendi o que P5 disse em relação à "identidade e pertencimento" assim: se eu me identifico, se eu pertenço a esse meio, eu vou lutar por ele. Vou lutar pelo fim da violência, vou ter que lutar pelo fim dessa desigualdade. Entende? (P6).

Constatou-se, nas falas de P5, P6 e D1, que questões como "Cidadania", "Valores", "Violência", "Meio Ambiente", "Identidade e Pertencimento" necessitam ser levadas e discutidas de forma emergencial em sala de aula. Pode-se inferir, com base nas falas, que há indicativos da superação do Medo da Liberdade, à medida que os professores elegem questões para serem trabalhadas em sala de aula, que emergem das necessidades de Olivença e extrapolam o livro didático. Isso porque os professores afastam-se dos conteúdos tradicionalmente bancários, já estabelecidos 
previamente, para contemplar assuntos vinculados à realidade do aluno (Rocha, 2013). Com isso, o docente aproxima-se da construção de um currículo crítico e reflexivo no ensino de Ciências, que influencia em novos processos organizacionais, promovendo a reconstrução de novos sentidos, significados, valores e ideologias na escola (Silva, 2004).

Há uma sintonia entre os posicionamentos dos professores com as ideias de Alves e Silva (2015), pois P5, P6 e D1 ao assumirem uma postura autônoma, distanciam-se da reprodução dos conteúdos pré-estabelecidos, apresentando a possibilidade de trabalhar em sala de aula questões que permeiam a realidade do aluno, fomentam, a implementação do currículo crítico reflexivo defendido pelos autores.

Na etapa da Organização da Programação Curricular, ocorreu a elaboração de Planos de Aula, seguindo a dinâmica dos Três Momentos Pedagógicos (Delizoicov, Angotti e Pernambuco, 2009). Constatou-se que os docentes não selecionaram qualquer conteúdo a ser trabalhado em sala de aula, a priori identificaram as situações-limites e na sequência apontaram o conteúdo científico necessário para a compreensão crítica da mesma, conforme o extrato da fala: "Os impactos causados pelo areal, temos que falar. Desmatamento, Destruição (P4)." P4 aponta

40 a necessidade de trabalhar assuntos relacionados ao desmatamento e destruição ambiental para que os moradores possam compreender os impactos causados pela extração de areia. Esse posicionamento está vinculado à situação-limite que denota uma alienação por parte dos moradores, diante dos problemas causados pelo areal, expressos nos extratos das falas:

Eu fiquei muito surpresa com o areal, é aquela questão mesmo, dá problema, prejuízo para todo mundo, mas, mas ele financia isso, financia aquilo. Esse é o grande problema e as pessoas ganham nesse aspecto, entendeu? Ele dá patrocínio, ele financia, seu filho está doente, precisa ir para São Paulo, ele vai lá paga a passagem, Entendeu? Então, é esse lado. Parece com o tráfico no Rio de Janeiro, sabe? É um tráfico que a gente não quer, mas ele ajuda a comunidade (P3).

Na análise dessa situação-limite, P3 elenca os conteúdos da sua área que considera relevante para que os sujeitos compreendam que essa atividade extrativista pode gerar inúmeros problemas ambientais para Olivença. Para além da seleção de conteúdos, conhecimentos e ações, os educadores estruturaram o Tema Gerador em três Unidades de Ensino: I - Identidade Histórica de Olivença; II - Impactos socioambientais; III - Infraestrutura e Economia. 
Há indícios da superação do Medo da Liberdade, à medida que os professores apresentam-se ativos no processo de estruturação das Unidades de Ensino e seleção dos conteúdos. As posturas de P3, P5, P6 e D1 apresentam indicativos da superação da cultura arraigada na Rede Pública brasileira, a qual compreende que os conteúdos escolares estão pré-estabelecidos em apostilas, livros didáticos e documentos oficiais. Além disso, constata-se na estruturação da Unidade Il, que os professores compreenderam a relevância de discutir em sala de aula os impactos causados pelo areal. Tal posicionamento indica a superação do Medo, pois mesmo sabendo que os responsáveis são sujeitos violentos e uma parte da comunidade defende a extração de areia, os professores não se intimidaram e apontaram a necessidade de discutir essa questão em sala de aula.

\subsection{Pretensão à verdade científica}

O Obstáculo da Pretensão à Verdade Científica foi manifestado pelos professores no estudo de Bomfim (2018) quando eles reduziram o processo de ensino e aprendizagem à transmissão de conteúdos comprovados cientificamente, caracterizando a educação como uma verdadeira invasão cultural. Como mencionado anteriormente, na etapa da Aproximação inicial com a comunidade local e escolar, realizou-se problematizações com os professores por meio do vídeo "A coroa do Imperador", buscando compreender, como os mesmos realizavam os planejamentos de suas aulas. Quando se questionou os educadores sobre a importância de levar em consideração a realidade dos alunos para a estruturação das aulas, P1 afirmou:

Eu apresento o conteúdo que eu quero trabalhar com eles e antes de iniciar eu procuro dar alguns exemplos que relacionem com o dia a dia deles. (P1).

P1 explicita que o planejamento da aula ocorre independente da realidade dos alunos, mas à medida que ministra o conteúdo tenta relacionar com o dia a dia dos mesmos. P3 corrobora com a ideia de P1 e afirma:

À noite já é outro público. Um público que você vai chegar, aí eles já vão tá muito mais calmos. Aí você vai passar o conteúdo. Você vai exemplificando, contextualizando aquilo que você tá na realidade (P3).

As situações expressas nas falas de P1 e P3 explicitam que a base da estruturação das aulas não está vinculada à realidade do aluno, sendo esta utilizada apenas para exemplificar questões do conteúdo ministrado. Nessas condições, o ensino e a aprendizagem ocorrem ignorando o conhecimento e as contradições sociais vividas pelos educandos (Alves, 2014). 
Para Alves (2014), o Obstáculo Gnosiológico Pretensão à verdade Científica manifesta-se no contexto escolar quando o docente estabelece uma prática unidirecional, por meio da imposição de sentidos, valores e significado, desconsiderando os conhecimentos, a cultura e a participação dos alunos. Os conteúdos ministrados por P1 e P3 são selecionados sem considerar os problemas vivenciados pela comunidade, supervalorizando os conteúdos pré-estabelecidos pela programação curricular da escola, independe do significado que os mesmos apresentam para os alunos.

No contexto da EJA, a manifestação da Pretensão à verdade científica é um problema ainda maior, pois Freire (1987) afirma que a educação de adultos (na perspectiva da educação popular) exige à compreensão do conteúdo e à sensibilidade dos educadores. Uma destas exigências também está associada à necessidade dos educadores compreenderem as contradições sociais vividas pelos alunos. No entanto, tal postura não é expressa nas falas de P1 e P3, que utilizam da realidade do aluno apenas para citar exemplos. Para Freire (1987, p. 22), "não é possivel educadoras e educadores pensar apenas os procedimentos didáticos e os conteúdos a serem ensinados aos grupos populares" é preciso que os educadores possam conhecer a realidade da comunidade local e escolar, para trabalhar a partir das necessidades apresentadas pelos educandos. O autor aponta que a estruturação dos conteúdos não pode estar desvinculada da realidade da comunidade, mas deve servir como base para o desenvolvimento da prática pedagógica.

Na etapa da Apresentação de possíveis Situações-limite, nota-se que os professores trabalham em sala de aula com alguns elementos utilizados na Codificação e Descodificação, quando Pq3 questionou:

Mas iai?! As questões abordadas no vídeo e sistematizadas por vocês (professores) nos cartazes, como exemplo as questões ambientais, o areal, a poluição das praias. Vocês acham o quê? Poderiam ser trabalhadas em sala de aula? (Pq3) Acho que sim (P4.). De certa forma, alguns desses temas são trabalhados, mas não com tanta densidade. A gente conversa, ou seja, até que a gente tem algumas informações. Por exemplo, eu não moro aqui, mas eu já conheço bastante coisa por conta do debate que a gente faz aqui, que eles trazem as angústias, as preocupações. Mas, organizado dessa forma, a gente, realmente, não tinha trabalhado (P5).

Nos extratos das falas de P4 e P5, notou-se que os mesmos já trabalharam com algumas das temáticas apresentadas na Descodificação (no vídeo e nos cartazes construídos pelos Professores). Todavia, P5 ressalta que esse trabalho não ocorreu com a riqueza de detalhes sistematizados e apresentados na Codificação e Descodificação. Nessa etapa da Apresentação de possíveis Situações-limite não foram evidenciados posicionamentos dos docentes que expressaram indicativos da 
superação do Obstáculo Gnosiológica Pretensão à verdade científica. Contudo, as Codificações e Descodificações realizadas nessa etapa são relevantes para que os professores tenham um contato direto com algumas das problemáticas vivenciadas pela comunidade e possam utiliza-las na estruturação das aulas.

Para Freire (1987), a Codificação realizada na Investigação Temática corresponde às representações das situações existências, enquanto que as Descodificações referem-se à análise crítica desta "situação codificada". Silva (2004) argumenta que as Codificações e Descodificações são imprescindíveis na estruturação de uma proposta educacional, uma vez que, por meio destas, serão discutidas e legitimadas as contradições sociais vivenciadas pela comunidade local e escolar. Assim, com o vídeo "Bem Vindo(a) a Olivença" foram apresentados aos professores características específicas (histórico, econômicos, cultural) daquele espaço, motivando P5 perceber que há possibilidade de sistematizar as informações acerca das problemáticas de Olivença.

A Descodificação, entendida por Freire (1987, p. 6) como a "análise e consequente reconstituição da situação vivida", pode auxiliar na superação da Pretensão à Verdade Científica, uma vez que fomenta no sujeito o desenvolvimento de um olhar sistematizado e crítico da sua realidade, bem como propicia a compreensão de problemáticas que na maioria das vezes são desconhecidas. Isto ocorre, pois na Descodificação, durante o Processo de Formação, o professor analisa as informações da realidade da comunidade, explanando sua concepção sobre os recortes apresentados.

Na etapa da Organização da Programação Curricular, os professores elencaram alguns conhecimentos, conteúdos e ações para a superação das visões limitadas apresentadas pela comunidade e poder público, apontando indicativos da superação do Obstáculo Pretensão à verdade científica, como ilustra a fala de P5:

Acho que seria interessante também estudarmos a cultura indígena. Certo dia um aluno me falou que não gostava de índios, que achava todos preguiçosos. Eu expliquei que não era bem assim, eles apresentavam outros costumes e outra cultura. Por isso, e acho interessante trabalhar a cultura indígena em sala de aula. O que á cultura indígena? Até eu mesmo não sabia dessa história do massacre do cururupe (fato apresentado no vídeo). Porque o não conhecimento da história leva a essa desvalorização do povo indígena (P5). 
O professor P5 apontou a necessidade de trabalhar em sala de aula aspectos da cultura indígena, pois o mesmo entende que o desconhecimento da história e cultura leva a descriminação e desvalorização dos índios. Já P2, referiu-se uma visão equivocada expressa na fala de um aluno e afirmou:

Tenho que trabalhar também o "salitro" (referindo a um termo da fala de um aluno). Nesse caso, envolvem as propriedades químicas e físicas. Dá para trabalhar um monte de coisa (P2).

Com relação aos aspectos relacionados ao areal, P4 ressaltou a importância de abordar os impactos ambientais causados pela extração da areia: "Da parte do areial, temos que falar dos impactos, como o desmatamento. Podemos falar também dos impactos da extração da areia sobre os ciclos biogeoquímicos (P4)".

Os extratos das falas de P2, P4 e P5 evidenciam que os professores durante as aulas ministradas, elencaram alguns conhecimentos relevantes para a superação de algumas compreensões limitadas apresentadas pela comunidade de Olivença. Ao assumir essa postura, os professores opõe-se a cultura impregnada nos espaços formais de ensino, que defende uma prática pedagógica tradicional, com currículos historicamente preestabelecidos. Para Silva (2004), um dos desafios encontrados na escola está relacionado à seleção de conteúdos que condizentes com a realidade dos alunos, pois normalmente os docentes aceitam conteúdos disciplinares que não condizem com os sujeitos e com o contexto que os mesmos estão inseridos.

Identificou-se, também, a superação em algumas compreensões de P4, se comparado com seu posicionamento na entrevista semiestruturada realizada por Bomfim (2018), quando o mesmo afirma que:

A realidade deve servir de base, mas não é isso que acontece e é muito difícil fazer isso. Eu acho que é o ideal, mas não é o real. Não é o que eu faço (P4) Bomfim (2018, p.111).

Nessa fala, P4 considera que no cenário educacional ideal, a realidade dos alunos deve orientar o desenvolvimento das aulas, mas na prática isso não ocorre. Durante o Processo Formativo esse mesmo professor admite a relevância de estabelecer alguns conteúdos a partir dos problemas ambientais causados pela extração da areia.

Os extratos das falas de P2, P4 e P5 estão em consonância com as análises de Alves (2014), pois a autora argumenta que o processo de ensino e aprendizagem em que os limites explicativos da realidade dos educandos são considerados, rompem com a imposição de visões, conhecimento, ideias e significados. Para Freire (1981, p. 
14), uma prática educativa efetiva não se dá de forma aleatória, mas consideram-se aspectos do "contexto concreto, histórico, social, cultural, econômico, político". Nessa perspectiva, o ensino não ocorre a partir da invasão cultural, mas por meio da demanda social dos sujeitos.

Ao elencar os conteúdos a serem ministrados na sala de aula, a partir da realidade dos alunos, P2, P4 e P5 rompem com os pressupostos da escola tradicional, uma vez que esses fomentam a "separação dos sujeitos a partir de conteúdos alienados e alienantes, anacrônicos e descontextualizados" (Silva, 2004, p. 19). Com isso, os professores superam um cenário educacional, o qual é impregnado pela memorização de conteúdos e utilizam-se da realidade dos alunos apenas para citar exemplos.

\subsection{Arrogância epistemológica}

No primeiro encontro do Processo Formativo, em que se buscou compreender as visões dos educadores sobre o papel do professor, identificou-se o Obstáculo Gnosiológico da Arrogância Epistemológica, expressa por P1:

Assim, que houve muito conflito (professor e os alunos), porque eu queria ensinar algo que eles (alunos) não estavam aptos a receber. Tanto que esse ano, eu trabalho no segundo e terceiro ano também, e eu não dou o conteúdo da série. Eu faço revisão, porque não adianta dar o conteúdo que é da série, porque eles não vão pegar (P1).

No discurso P1, nota-se que sua relação com os alunos é permeada por alguns conflitos, associados ao fato do professor entender que os educandos não estão habilitados para "pegar" determinados conteúdos. Como consequência desta situação, o docente seleciona os conteúdos que julga condizente com a "aptidão" do aluno "receber". Para Freire (1996), um educador deve respeitar os saberes dos educandos, pois chegam deles saberes que são socialmente construídos na prática. Essa não foi a postura assumida por P1, uma vez que não há valorização dos saberes dos educandos. Tendo como referência Alves e Silva (2015), constata-se a Arrogância Epistemológica na fala de P1, uma vez que o educador apresenta-se intolerante com os conhecimentos e limites explicativos apresentados pelos alunos. Alves (2014) argumenta que os professores ao estarem imersos nesse Obstáculo ignoram que o processo de ensino e aprendizagem deve ocorrer de forma horizontal, considerando os educandos como sujeitos ativos do processo. 
Na etapa da Legitimação da Hipótese foram problematizadas as situações-limite evidenciadas na Codificação e na Descodificação, com objetivo de legitimar o Tema Gerador "Olivença: eu vivo em um paraíso esquecido". Neste momento, P3 manifestou interesse em trabalhar com a proposta, afirmando a possibilidade de compreender algumas questões da realidade de Olivença:

Eu vejo assim, então assim, ao meu ver. Gostei, eu quero fazer essa proposta! Assim, é, tem esse medo, tem um pouco de conhecimento (com relação à realidade da comunidade)? Sim! Mas esse conhecimento que eu não tinha, tem que tá buscando. Mas a maioria é medo mesmo, é medo! (P3).

O extrato da fala de P3 denota humildade em reconhecer a necessidade de novos conhecimentos relacionados à comunidade de Olivença para trabalhar a partir do Tema Gerador. Ao assumir essa postura, P3 rompe com as barreiras da arrogância e compreende que o processo de ensino e aprendizagem não ocorre numa relação autoritária, mas se dá na construção coletiva de conhecimentos em que educando e educador apresentam saberem fundamentais que precisam ser respeitados em todo o processo (Alves, 2014).

Dussel (1995, p.8) aponta que ao "aceitar o argumento do outro supõe aceitar ao outro como igual, e esta aceitação do outro como igual é uma posição ética, é o reconhecimento ético ao outro como igual". O autor reitera que a relação igualitária estabelecida entre os sujeitos, proporciona a desconstrução do sistema opressor, permitindo que os oprimidos possam participar ativamente das tomadas de decisões. Com isso, o sujeito que anteriormente era opressor passa assumir uma nova postura, valorizando os saberes dos outros sujeitos (antes vistos como objetos). Freire (1997, p. 37) argumenta que ao assumir uma postura humilde o docente reconhece que "ninguém sabe tudo; ninguém ignora tudo. Todos sabemos algo; todos ignoramos algo. Sem humildade dificilmente ouviremos com respeito a quem consideramos demasiadamente longe de nosso nível de competência". Isto é, tanto os discentes como docentes apresentam saberes que precisam ser respeitados, levando o educador a compreender que o processo de ensino e aprendizagem não ocorre de forma unilateral, mas se constitui em um coletivo.

\section{CONSIDERAÇÕES FINAIS}

O desenvolvimento do presente Processo Formativo apresenta potencial Gnosiológico, uma vez que há indicativos da superação dos seguintes Obstáculos Gnosiológicos, nas etapas do processo de Investigação Temática: 
Negação Epistemológica como Gênese do Conhecimento: nas etapas da Legitimação da Hipótese e Organização da Programação curricular em que os educadores expressaram maior consciência com relação aos critérios utilizados para a seleção de conhecimento a partir do Tema Gerador, e constatam o papel social do conteúdo escolar, compreendendo que a seleção dos conteúdos científicos deve ocorrer a partir da demanda social da comunidade;

Medo da Liberdade: foi localizada na etapa da Aproximação com a comunidade local e escolar, todavia, nas etapas subsequentes há indicativos da superação deste obstáculo principalmente relacionado à seleção dos conteúdos que serão ministrados, tendo maior destaque na quarta etapa que corresponde a Organização da Programação Curricular. Isto ocorre quando o educador compreende-se como sujeito ativo do processo, autônomo para selecionar os conteúdos relevantes para que os educandos compreendam as situações-limite que envolvem o Tema Gerador. Além disso, ao superar o medo na sua prática, o docente cria expectativas de superação dos problemas locais, motivando a comunidade local e escolar buscar por melhores condições para o Distrito de Olivença.

Pretensão à verdade científica: identificada na etapa da Aproximação com a comunidade local e escolar e na segunda etapa - Apresentação de possíveis Situações-limite - foram apresentados alguns indicativos de que as informações obtidas nas Codificações e Descodificações proporcionarão subsídios para que nas etapas posteriores, os professores possam estruturar suas práticas pedagógicas a partir das informações sistematizadas sobre a realidade dos educandos. Já na quarta etapa - Organização da Programação Curricular- há indicativos da superação da Pretensão à verdade científica, durante a construção da Rede Temática. Com isso, a Investigação Temática fomentou a importância de dialogar com a comunidade de Olivença, obtendo-se a visão de mundo dos sujeitos que nela vivem que será ponto de referência para selecionar e elaborar os conteúdos e conhecimentos necessários para serem trabalhados em sala de aula.

Arrogância epistemológica: presente na Aproximação com a comunidade local e escolar. Não obstante, na etapa da Legitimação da Hipótese há indicativos da superação deste obstáculo, em que professores assumem uma postura humildade, ressaltando que precisar conhecer mais da realidade de Olivença para trabalhar com o Tema Gerador em sala de aula. Com isso, os professores reconhecem a educação como um processo de compreensão da realidade que os sujeitos estão inseridos, com vistas à possibilidade de análise crítica e transformação das problemáticas sociais apontadas ao longo da Investigação Temática. 
Para melhor compreender a superação dos Obstáculos Gnosiológicos durante o Processo Formativo de professores, laborou-se a Escala Gnosiológica que ilustra a manifestação dos obstáculos, bem como a superação dos mesmos, durante as etapas da Investigação Temática, conforme apresentado na Figura 1.

FIGURA 1

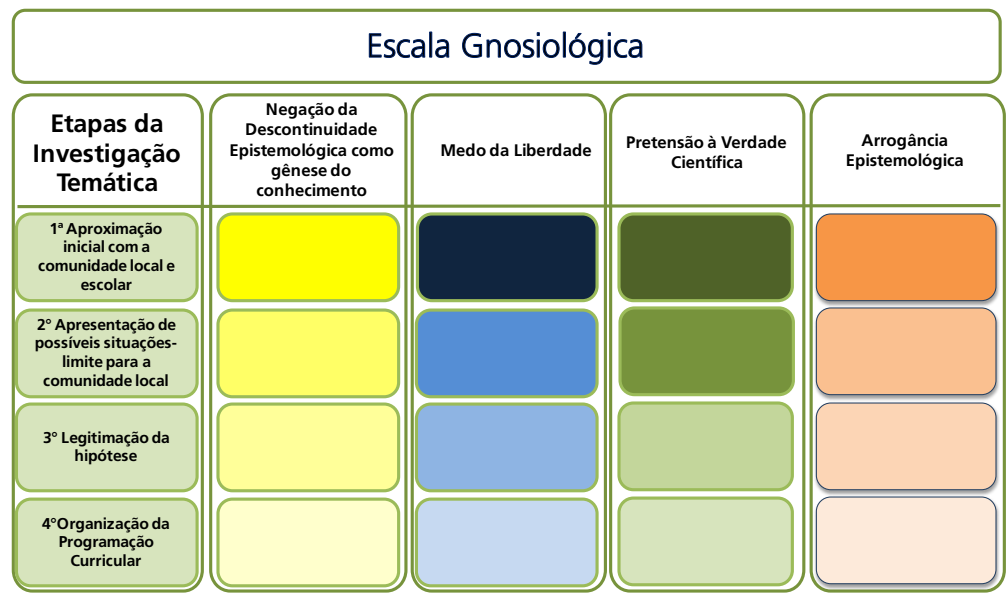

Fonte: Bomfim (2018, p.119).

A Escala, composta pelas etapas da Investigação Temática (coluna vertical) e pelos Obstáculos Gnosiológicos (primeira linha horizontal), ilustra a síntese das compreensões apresentadas pelos professores, ao decorrer do Processo Formativo realizado em Olivença. As tonalidades escuras representam a manifestação do Obstáculo, enquanto que as tonalidades claras apresentam indicativos da superação dos mesmos. O principal objetivo desta escala consiste em ilustrar a variação do Obstáculo, apresentando as etapas da Investigação que mais contribuíram para a superação do mesmo, que nesse caso, corresponde a Legitimação da Hipótese e Organização da Programação Curricular.

As análises do Processo Formativo corroboram com os apontamentos realizados por Coelho (2010), Alves e Silva (2015) e Bomfim (2018), ao afirmarem que o desenvolvimento de Processos Formativos balizados nos pressupostos freireanos pode indicar a superação de situações-limite em uma dimensão pedagógica. Além disso, constata-se que o Potencial Gnosiológico da Abordagem Temática Freireana é o primeiro passo para a superação dos Obstáculos Gnosiológicos, pois o mesmo pode propiciar outros elementos, sinalizados por Stuani (2016), como a reflexão em torno da prática (praxiológia), a seleção dos conteúdos científicos (epistemologia) e a compreensão das vivencias da comunidade (ontologia). Defende-se, assim, a 
formação docente na perspectiva freireana, em que a formação não está limitada aos cursos de capacitação, oficinas ou palestras, mas ocorre ao longo de toda vida. Essa formação, entendida como permanente (Stuani, 2016) proporciona ao docente momentos de reflexão crítica sobre sua própria prática, fomentando compreensões que o processo de ensino e aprendizagem ocorre a partir da realidade da comunidade local e escolar.

\section{REFERÊNCIAS}

Alves, A. H. B. (2014). Manifestações de obstáculos gnosiológicos para a seleção de conteúdos na implementação de um currículo crítico em ciências. (Dissertação Mestrado). PPGE: UFSCar, Sorocaba.

Alves, A. H. B. e Silva, A. F.G. (2015). Manifestações de Obstáculos Gnosiológicos para a Seleção de Conteúdos na Implementação de um Currículo Crítico em Ciências Naturais. Alexandria: Revista de Educação em Ciência e Tecnologia, 8 (1),1812017. Recuperado de: https://periodicos.ufsc.br/index.php/alexandria/article/ view/1982-5153.2015v8n1p181.

Alves, A. H. B. (2012). Critérios para a seleção dos conteúdos: a importância da contextualização para o ensino de ciências (Monografia). Universidade Federal de São Carlos, Sorocaba.

Bomfim, M. G. (2018). O Potencial Gnosiológico da Abordagem Temática Freireana: um olhar sobre o processo formativo de professores da EJA. (Dissertação Mestrado). PPGEC, UESC, Ilhéus, Bahia.

Coelho, J. C.(2010). Processos Formativos na Direção da Educação Transformadora: temasdobradiça como contribuição para abordagem temática (Tese Doutorado). PPGECT, UFSC, Florianópolis.

Delizoicov, D. (1982). Concepção problematizadora do ensino de ciências na educação formal: relato e análise de uma prática educacional na Guiné Bissau. (Dissertação Mestrado). USP, São Paulo.

Delizoicov, D., Angotti, J. A., e Pernambuco, M. M. (2009). Ensino de Ciências: Fundamentos e Métodos (4a. ed.). São Paulo: Cortez.

Dussel, E. (1995). Filosofia da Libertação: crítica à ideologia da exclusão. Trad. de George I. Maissiat. São Paulo: Paulus.

Freire, P. (1968). Educação como prática para liberdade. 29 ed. Rio de Janeiro: Paz e Terra.

Freire, P. (1981). Ação cultural para a liberdade. 5. ed. Rio de Janeiro: Paz e Terra.

Freire, P. (1987). Pedagogia do Oprimido. 17 ed. Rio de Janeiro: Paz e Terra. 
Freire, P. (1996). Pedagogia da autonomia: saberes necessários à prática educativa. São Paulo: Paz e Terra.

Freire, P. (1997). Professora sim, tia não. São Paulo: Olho D'água.

Japiassú, H., e Marcondes, D. (2001). Dicionário Básico de. Filosofia $3^{a}$ ed. Rio de Janeiro.

Lambach, M. (2013). Formação Permanente de Professores de Química da EJA na Perspectiva Dialógico-Problematizadora Freireana (Tese de Doutorado). PPGECT, UFSC, Florianópolis.

Moraes, R., \& Galiazzi, M. C. (2011). Análise Textual Discursiva. (2a. ed.) Ijuí: UNIJUí.

Rocha, C.C. (2013). "Bora vê quem pode mais": Uma etnografia sobre o fazer política entre os Tupinambá de Olivença (Ilhéus, Bahia) (Tese de doutorado). PPGAS, UFSC, Florianópolis.

Silva, A. F. G. (2004). A construção do currículo na perspectiva popular crítica: das falas significativas às práticas contextualizadas (Tese de doutorado). PUC, São Paulo, São Paulo.

Sousa, P. S., Solino, A. P., Figueiredo, P. S., \& Gehlen, S. T. (2014). Investigação Temática no Contexto do Ensino de Ciências: Relações entre a Abordagem Temática Freireana e a Práxis Curricular via Tema Gerador. Alexandria - Revista de Educação em Ciência e Tecnologia, 7(2), 155-177. Recuperado de: https://periodicos.ufsc.br/ index.php/alexandria/article/view/38222.

Stuani, G. M. (2016). Abordagem Temática Freireana: uma concepção de formação permanente dos professores de Ciências (Tese de doutorado). PPGECT, UFSC, Florianópolis. 